\title{
Low Red Blood Cell Count as an Early Indicator for Myometrial Invasion in Women with Endometrioid Endometrial Carcinoma with Metabolic Syndrome
}

This article was published in the following Dove Press journal: Cancer Management and Research

\author{
Yao Tong $\mathbb{D}^{1, *}$ \\ Xiaoyan $\mathrm{Xie}^{2, *}$ \\ Xiaodan Mao (D) ${ }^{1,3}$ \\ Huifang Lei $\mathbb{D}^{\prime}$ \\ Yaojia Chen (iD) \\ Pengming Sun (DI ${ }^{1-3}$ \\ 'Laboratory of Gynecologic Oncology, \\ Fujian Maternity and Child Health \\ Hospital, Affiliated Hospital of Fujian \\ Medical University, Fuzhou 35000I, \\ People's Republic of China; ${ }^{2}$ Department \\ of Gynecology, Fujian Maternity and Child \\ Health Hospital, Affiliated Hospital of \\ Fujian Medical University, Fuzhou 35000I, \\ People's Republic of China; ${ }^{3}$ Fujian Key \\ Laboratory of Women and Children's \\ Critical Diseases Research, Fujian \\ Maternity and Child Health Hospital, \\ Fuzhou 35000I, People's Republic of \\ China
}

*These authors contributed equally to this work
Purpose: We investigated the relationship between metabolic syndrome (MetS) and its components and erythrocyte parameters such as red blood cell count (RBC) and hemoglobin $\mathrm{Hb})$ levels, and their association with the risk of deep myometrial invasion in endometrioid endometrial carcinoma (EEC).

Patients and Methods: A total of 473 women diagnosed with EEC between January 2012 and December 2018 were included in the study. MetS was diagnosed using a modified version of the Chinese Diabetes Society 2004 criteria. Demographic and clinical characteristics were stratified by MetS and compared. Logistic regression analyses were performed to calculate the odds ratios (ORs) of myometrial invasion.

Results: The prevalence of MetS was 18.8\% (89/473). RBC and Hb levels were significantly higher in EEC patients with MetS. RBC and $\mathrm{Hb}$ values increased linearly with the number of MetS components. The OR of the MetS risk increased across the RBC quartiles $(\mathrm{OR}=2.212,95 \%$ confidence interval $[\mathrm{Cl}]=1.125-4.350, \mathrm{P}<0.05)$. Among EEC patients with MetS, the OR of deep myometrial invasion increased with the decrease of the RBC quartiles $(\mathrm{P}=0.037)$. Similarly, in EEC patients with obesity and hyperglycemia or with $\geq 2$ MetS criteria, the lowest $\mathrm{RBC}$ level (Q1) was a risk factor for deep myometrial invasion compared with the reference $\mathrm{RBC}$ group $(\mathrm{Q} 4, \mathrm{P}<0.05)$. However, this trend was not evident in $\mathrm{EEC}$ patients without MetS and its components.

Conclusion: EEC with MetS and its components had higher RBC and $\mathrm{Hb}$ levels. The association between the erythrocyte parameters and myometrial invasion differed with MetS. $\mathrm{RBC}$ was identified as a risk factor of myometrial invasion in EEC patients with MetS and its components.

Keywords: metabolic syndrome, endometrioid endometrial carcinoma, red blood cell count, hemoglobin, myometrial invasion

\section{Introduction}

Endometrioid endometrial carcinoma (EEC) is a common gynecological tumor, and its prevalence is increasing over the past few decades. The increased incidence of EEC could be related to a greater overall prevalence of obesity and metabolic diseases (obesity, hyperglycemia, and hyperlipidemia), in addition to the aging of the population. ${ }^{1}$ Prognostic factors for EEC have been investigated detailly, and the most important are the surgical FIGO (International Federation of Gynecology and Obstetrics) stage, depth of myometrial invasion, histologic tumor grade, and lymph node status. ${ }^{1}$ Therefore, it is very important to identify the subgroups of EEC
Correspondence: Pengming Sun Laboratory of Gynecologic Oncology Fujian Maternity and Child Health Hospital, Affiliated Hospital of Fujian Medical University, No. 18 Daoshan Road Fuzhou 35000I, Fujian, People's Republic of China

Tel $+8659 \mid 87558732$

Fax +86 591 87551247

Email sunfemy@hotmail.com
Cancer Management and Research 2020:12 10849-10859

10849 
patients with a higher risk of poor outcomes to provide accurate and appropriate individualized treatment and lifestyle guidance for adaptation.

Metabolic syndrome (MetS) is a complex disorder defined by a cluster of coexistent metabolic abnormalities characterized by insulin resistance including obesity, hypertension, hyperglycemia, and dyslipidemia. ${ }^{2}$ The prevalence of MetS is high in EEC patients, while the prognosis of EEC patients with MetS is poor. ${ }^{3}$

Inflammation is the core stage of tumorigenesis and development. ${ }^{4}$ The molecules associated with MetS do not only directly act on tumor cells but also promote the development and progression of endometrial cancer by further remodeling the tumor immune microenvironment. ${ }^{5}$ Anemia of inflammation due to prolonged immune activation is common in cancer patients. ${ }^{6}$ Although chronic inflammation may inhibit erythropoiesis, ${ }^{7,8}$ several studies have reported that MetS patients with a low degree of inflammation are often accompanied by increased erythropoiesis. These findings are relevant because, increased erythropoiesis may give these people a false impression of overall "good" health.

Therefore, the aim of this study was to explore the associations and clinical consequences of erythrocyte parameters such as red blood cell count (RBC) and hemoglobin $(\mathrm{Hb})$, and MetS on the risk of deep myometrial invasion in EEC.

\section{Patients and Methods}

\section{Study Patients}

This descriptive study is a retrospective study involving the medical records of patients diagnosed with EEC. From January 2012 to December 2018, 526 patients with EEC treated in the Fujian Maternal and Child Health Hospital were enrolled. Of these, 473 met the eligibility criteria, i.e., they had stage I-IV disease treated with hysterectomy and bilateral salpingoophorectomy, with or without pelvic and para-aortic lymph node dissection. Patients were staged based on the FIGO guidelines. The EEC histological subtype was diagnosed pathologically after operation. Patients with non-endometrioid histological subtypes or incomplete medical records were excluded. Sixteen patients with other concomitant cancers (3 ovarian, 4 breast, 3 rectal, and 6 other cancers) were excluded due to the possible confounding neoplastic effect on hematopoiesis. None of the patients had a past history of endometrial cancer or had received neoadjuvant chemotherapy or radiotherapy before operation. Finally, 473 patients were included for further analysis. The study was approved by the Ethics Committee of Fujian Maternity and Child Health Hospital, Affiliated Hospital of Fujian Medical University (No. 2020-2002) and was conducted according to the principles of the Declaration of Helsinki. As this retrospective study did not harm the rights and health of patients and protected their privacy and personal information, the ethics committee waived the requirement to obtain informed consent.

\section{Data Collection and Measurements}

Data were obtained from patients' files available through our institution's biochemical database. The anthropometric parameters, biochemistry, and hematological counts routinely collected before surgery during hospitalization were obtained. Ergonomic parameters were measured by trained personnel in accordance with standardized protocols. Height, weight, systolic blood pressure (SBP), and diastolic blood pressure (DBP) were measured multiple times and their averages calculated. Body mass index (BMI) was calculated by dividing the weight $(\mathrm{kg})$ by the height $\left(\mathrm{m}^{2}\right)$. The venous blood samples used in the analysis were taken before surgery. The median time from blood analysis to surgical treatment in our patient cohort was 2 (range 0 to 7) days.

\section{Definition of Metabolic Syndrome}

According to the criteria set forth by the Chinese Diabetes Society (CDS) in $2004,{ }^{9}$ a person was diagnosed with MetS when she had at least three of the following criteria: (I) obesity: BMI $\geq 25 \mathrm{~kg} / \mathrm{m}^{2}$, (II) hyperglycemia: fasting blood glucose $\geq 6.1 \mathrm{mmol} / \mathrm{L}$ or 2-hour plasma glucose $\geq$ $7.8 \mathrm{mmol} / \mathrm{L}$ or previously diagnosed diabetes, (III) dyslipidemia: triglycerides $\geq 1.7 \mathrm{mmol} / \mathrm{L}$ or high-density lipoprotein cholesterol (HDL) $<1.0 \mathrm{mmol} / \mathrm{L}$ in women, (IV) hypertension: systolic/diastolic blood pressure $\geq 140$ / $90 \mathrm{mmHg}$ or currently receiving antihypertensive therapy.

\section{Quartiles of Erythrocyte Parameter Levels}

Erythrocyte parameter levels were categorized into quartiles on the basis of individual distributions (RBC: Q1 < $4.00 \times 10^{\wedge} 12 / \mathrm{L}, \mathrm{Q} 2=4.00-4.27 \times 10^{\wedge} 12 / \mathrm{L}, \mathrm{Q} 3=4.28-$ $4.59 \times 10^{\wedge} 12 / \mathrm{L}, \mathrm{Q} 4>4.59 \times 10^{\wedge} 12 / \mathrm{L} ; \mathrm{Hb}: \mathrm{Q} 1<114 \mathrm{~g} / \mathrm{L}$, $\mathrm{Q} 2=115-125 \mathrm{~g} / \mathrm{L}, \mathrm{Q} 3=126-133 \mathrm{~g} / \mathrm{L}, \mathrm{Q} 4>134 \mathrm{~g} / \mathrm{L})$. 


\section{Statistical Analysis}

Quantitative data were analyzed using the Student's test or Mann-Whitney $U$-test, while qualitative variables were analyzed using the Chi-squared test. Continuous data and $\mathrm{RBC}$ and $\mathrm{Hb}$ levels were expressed as mean \pm standard deviation (SD). A one-way ANOVA and $\chi^{2}$ test were conducted to test the composition of MetS in the subjects according to the RBC count and hemoglobin quartile. Logistic regression analyses were performed to calculate the adjusted odds ratios (ORs) of the erythrocyte parameters associated with myometrial invasion by MetS and its components. All statistical analyses were performed using the Statistical Package for the Social Sciences (SPSS) V.22.0 (SPSS, Chicago, Illinois, USA). A P value $<0.05$ was considered statistically significant.

\section{Result}

\section{Patient Characteristics}

In total, $89(18.8 \%)$ of the 473 EEC patients were diagnosed with MetS. The average age of the MetS group was significantly higher than that of the non-MetS group $(\mathrm{P}=$ 0.001). MetS components were significantly more prevalent in all the MetS standard groups than in the non-MetS groups $(\mathrm{P}<0.001)$. Both $\mathrm{RBC}$ and $\mathrm{Hb}$ levels were

Table I Descriptive and Comparative Analysis of Demographics and Clinical Variables According to the Presence or Not of MetS

\begin{tabular}{|c|c|c|c|c|}
\hline Parameter & MetS+ $(n=89)$ & MetS- $(n=384)$ & P-value & Total $(n=473)$ \\
\hline Age (years) & $55.70 \pm 8.94$ & $52.60 \pm 8.03$ & $<0.001^{* *}$ & $(22-90)$ \\
\hline Menopause & $67(75.3 \%)$ & $215(56.0 \%)$ & $0.001 * *$ & $282(59.6 \%)$ \\
\hline \multicolumn{5}{|l|}{ Erythrocyte parameters } \\
\hline $\operatorname{RBC}\left(10^{\wedge} / 2 / L\right)$ & $4.40 \pm 0.48$ & $4.25 \pm 0.48$ & $0.008^{* *}$ & $(2.11-6.19)$ \\
\hline $\mathrm{Hb}(\mathrm{g} / \mathrm{L})$ & $125.57 \pm 15.80$ & $121.09 \pm 18.08$ & $0.024 *$ & $(52-161)$ \\
\hline \multicolumn{5}{|l|}{ MetS criteria } \\
\hline Criteria I MetS & $83(93.3 \%)$ & II 8 (30.7\%) & $<0.00 I^{* *}$ & 201 (42.5\%) \\
\hline Criteria II MetS & 74 (83.1\%) & 54 (I4.1\%) & $<0.00 I^{* *}$ & $128(27.1 \%)$ \\
\hline Criteria III MetS & 70 (78.7\%) & $106(27.6 \%)$ & $<0.00 I^{* *}$ & $176(37.2 \%)$ \\
\hline Criteria IV MetS & 70 (78.7\%) & 115 (29.9\%) & $<0.00 I^{* *}$ & $185(39.1 \%)$ \\
\hline No. of MetS criteria & & & $<0.00 I^{* *}$ & \\
\hline 0 & $0(0.0 \%)$ & $122(3 \mid .8 \%)$ & & $122(25.8 \%)$ \\
\hline I & $0(0.0 \%)$ & $|3|(34.1 \%)$ & & $|3|(27.7 \%)$ \\
\hline 2 & $0(0.0 \%)$ & $|3|(34.1 \%)$ & & $|3|(27.7 \%)$ \\
\hline 3 & 59 (66.3\%) & $0(0.0 \%)$ & & 59 (I2.5\%) \\
\hline 4 & $30(33.7 \%)$ & $0(0.0 \%)$ & & $30(6.3 \%)$ \\
\hline Stage & & & 0.649 & \\
\hline Early stage (FIGO I/II) & 81 (91.0\%) & 355 (92.4\%) & & $436(92.2 \%)$ \\
\hline Advanced stage (FIGO III/IV) & $8(9.0 \%)$ & $29(7.6 \%)$ & & $37(7.8 \%)$ \\
\hline Depth of myometrial invasion & & & $<0.00 I^{* *}$ & \\
\hline$<\mathrm{l} / 2$ & $54(60.7 \%)$ & $313(81.5 \%)$ & & 367 (77.6\%) \\
\hline$\geq \mathrm{I} / 2$ & 35 (39.3\%) & 71 (18.5\%) & & $106(22.4 \%)$ \\
\hline Lymph node metastases & & & 0.641 & \\
\hline Yes & $6(6.7 \%)$ & $21(5.5 \%)$ & & $27(5.7 \%)$ \\
\hline No & 81 (91.0\%) & $356(92.7 \%)$ & & 437 (92.4\%) \\
\hline Histologic tumor grade & & & 0.277 & \\
\hline GI & $41(46.1 \%)$ & $217(56.5 \%)$ & & $258(54.5 \%)$ \\
\hline G2 & 38 (42.7\%) & $130(33.9 \%)$ & & $168(35.5 \%)$ \\
\hline G3 & 10 (11.2\%) & $37(9.6 \%)$ & & $47(9.9 \%)$ \\
\hline
\end{tabular}

Notes: $* \mathrm{P}<0.05$; ** $\mathrm{P}<0.01$.

Abbreviations: MetS, metabolic syndrome; Criteria I MetS, body mass index (BMI) $\geq 25 \mathrm{~kg} / \mathrm{m}^{2}$; Criteria II MetS, fasting blood glucose $\geq 6$.I mmol/L or 2-hour plasma glucose $\geq 7.8 \mathrm{mmol} / \mathrm{L}$ or previously diagnosed diabetes; Criteria III MetS, triglycerides $\geq 1.7 \mathrm{mmol} / \mathrm{L}$ or high-density lipoprotein cholesterol (HDL) < I.0 mmol/L in women; Criteria IV MetS, systolic/diastolic blood pressure $\geq 140 / 90 \mathrm{mmHg}$ or currently receiving antihypertensive therapy. 
significantly higher in the MetS group than in the nonMetS group $(\mathrm{P}=0.008 ; \mathrm{P}=0.024)$. Among prognostic factors including FIGO stage, myometrial infiltration, lymphatic infiltration, and histological grade, the difference was only statistically significant in myometrial infiltration $(\mathrm{P}<0.001$, Table 1). We followed up 473 patients, with a median follow-up time of 45.5 months, the Kaplan-Meier analysis of OS are shown in Supplementary Figure 1.

\section{Relationship Between MetS and Erythrocyte Parameter Levels}

Circulating $\mathrm{Hb}$ and $\mathrm{RBC}$ levels were analyzed in the whole cohort of patients according to the 4 individual diagnostic criteria of MetS (obesity, hyperglycemia, dyslipidemia, hypertension; Table 2). RBC levels were significantly higher in patients with all the 4 MetS criteria than those who did not $(\mathrm{P}<0.05)$. Hb levels were higher in patients with hyperglycemia and hypertension $(\mathrm{P}<0.05$, Table 2$)$.

Figure 1 shows that the characteristics of the $473 \mathrm{sub}-$ jects classified into the various $\mathrm{RBC}$ and $\mathrm{Hb}$ quartiles. The prevalence of MetS increased in a dose-dependent manner with an increase in RBC and $\mathrm{Hb}$ levels. However, the difference was not statistically significant $(\mathrm{P}=0.119, \mathrm{P}=$ 0.078). We compared the prevalence of abnormal MetS parameters in the $\mathrm{RBC}$ and $\mathrm{Hb}$ quartiles. The prevalence of obesity and dyslipidemia was significantly higher with an increase in $\operatorname{RBC}(\mathrm{P}=0.014, \mathrm{P}=0.012)$. There was no statistically significant difference in the prevalence of dyslipidemia and hypertension in the different $\mathrm{RBC}$ quartiles $(\mathrm{P}$ $=0.073, \mathrm{P}=0.307)$. The prevalence of hyperglycemia and hypertension was significantly different among different $\mathrm{Hb}$ quartiles $(\mathrm{P}=0.030, \mathrm{P}=0.001)$, while there was no statistically significant difference in the prevalence of obesity and hyperglycemia $(\mathrm{P}=0.402, \mathrm{P}=0.057)$.

We also calculated the mean $\mathrm{RBC}$ and $\mathrm{Hb}$ concentration by the MetS components. RBC levels increased linearly with an increase in the number of MetS components from 0 to $4(\mathrm{P}=0.002)$. Especially, the mean concentration of RBC significantly increased above the two parameters of the MetS components $(\mathrm{P}<0.05)$. There was a significant increasing trend in the $\mathrm{Hb}$ levels with the presence of $\leq 3$ MetS components $(P=0.042$; Figure 2).

Adjusted ORs of MetS and its components associated with $\mathrm{RBC}$ or $\mathrm{Hb}$ quartiles are listed in Table 3. As the concentration of $\mathrm{RBC}$ or $\mathrm{Hb}$ increased, the lowest quartile was considered as the reference group. After adjusting for age, the OR of MetS risk increased across the RBC quartiles $(\mathrm{OR}=$ $2.212,95 \%$ confidence interval $[\mathrm{Cl}]=1.125-4.350 ; \mathrm{P}<0.05)$. With reference to the lowest $\mathrm{RBC}$ quartile (Q1), the OR was 2.322 for the highest RBC quartile (Q4) in the obese patients and 2.288 for RBC (Q4) in the patients with hyperglycemia. Compared with $\mathrm{Hb}$ (Q1), the OR for being hypertensive increased across the $\mathrm{Hb}$ quartiles, even when adjusted by age $(\mathrm{OR}=2.028,95 \% \mathrm{Cl}=1.123-3.663 ; \mathrm{P}<0.05)$.

Table 2 The Relationship Between RBC Level, Hb Level, and MetS Criteria (I, II, III, or IV)

\begin{tabular}{|c|c|c|c|c|c|}
\hline MetS Criteria & $\mathbf{n}$ & $\operatorname{RBC}\left(10^{\wedge} \mid 2 / L\right)$ & P-value & $\mathrm{Hb}(\mathrm{g} / \mathrm{L})$ & P-value \\
\hline \multicolumn{6}{|l|}{ MetS } \\
\hline Yes & 89 & $4.40 \pm 0.48$ & $0.008 * *$ & $|25.57 \pm| 5.80$ & $0.024 *$ \\
\hline No & 384 & $4.25 \pm 0.48$ & & $121.09 \pm 18.08$ & \\
\hline \multicolumn{6}{|l|}{ Criteria I MetS } \\
\hline Yes & 201 & $4.35 \pm 0.49$ & $0.012 *$ & $122.96 \pm 18.14$ & 0.155 \\
\hline No & 272 & $4.23 \pm 0.48$ & & $121.18 \pm 17.45$ & \\
\hline \multicolumn{6}{|l|}{ Criteria II MetS } \\
\hline Yes & 128 & $4.40 \pm 0.49$ & $0.001 * *$ & $124.76 \pm 17.82$ & $0.009 * *$ \\
\hline No & 345 & $4.24 \pm 0.47$ & & $|20.89 \pm| 7.63$ & \\
\hline \multicolumn{6}{|l|}{ Criteria III MetS } \\
\hline Yes & 176 & $4.34 \pm 0.52$ & $0.014^{*}$ & $|22.6| \pm \mid 8.23$ & 0.298 \\
\hline No & 297 & $4.25 \pm 0.46$ & & $|2| .54 \pm \mid 7.48$ & \\
\hline \multicolumn{6}{|l|}{ Criteria IV MetS } \\
\hline Yes & 185 & $4.33 \pm 0.49$ & $0.043^{*}$ & $125.62 \pm 14.69$ & $0.00 I^{* *}$ \\
\hline No & 288 & $4.25 \pm 0.48$ & & $119.57 \pm 19.11$ & \\
\hline
\end{tabular}

Notes: ${ }^{*} \mathrm{P}<0.05$; $* * \mathrm{P}<0.01$.

Abbreviations: MetS, metabolic syndrome; RBC, red blood cell count; Hb, hemoglobin. 

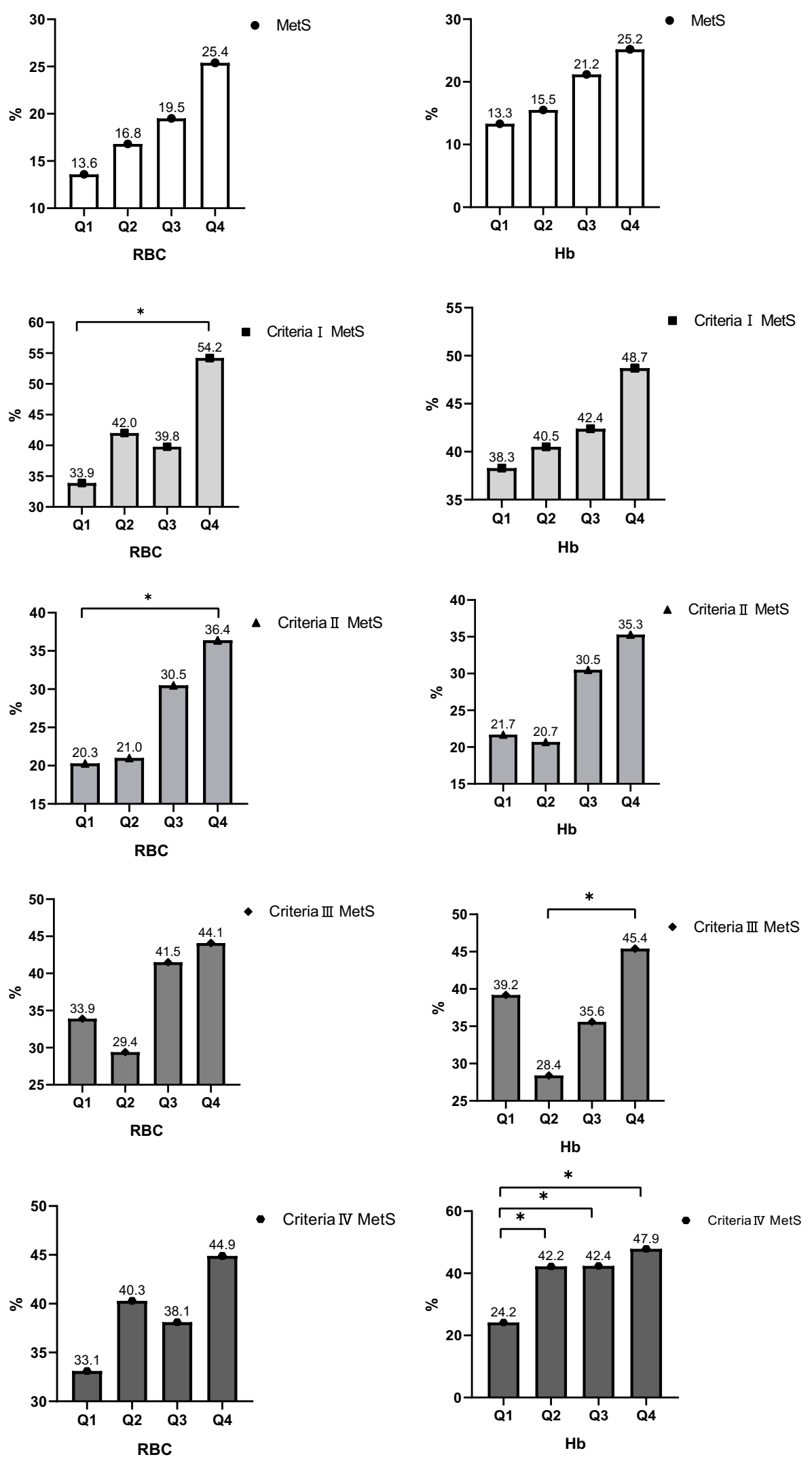

Figure I Prevalence of MetS and its components according to the quartile of RBC and $\mathrm{Hb}$ levels in blood.

Note: ${ }^{*} \mathrm{P}<0.05$

Abbreviations: MetS, metabolic syndrome; RBC, red blood cell count; Hb, hemoglobin; QI, Ist quartile; Q2, 2nd quartile; Q3, 3rd quartile; Q4, 4th quartile. 


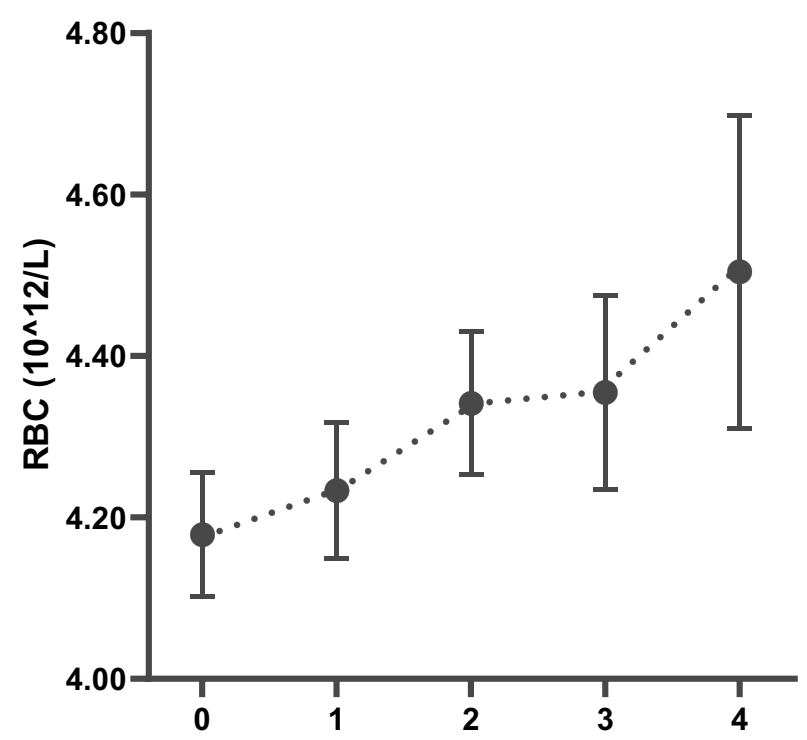

Sum of metabolic syndrome components

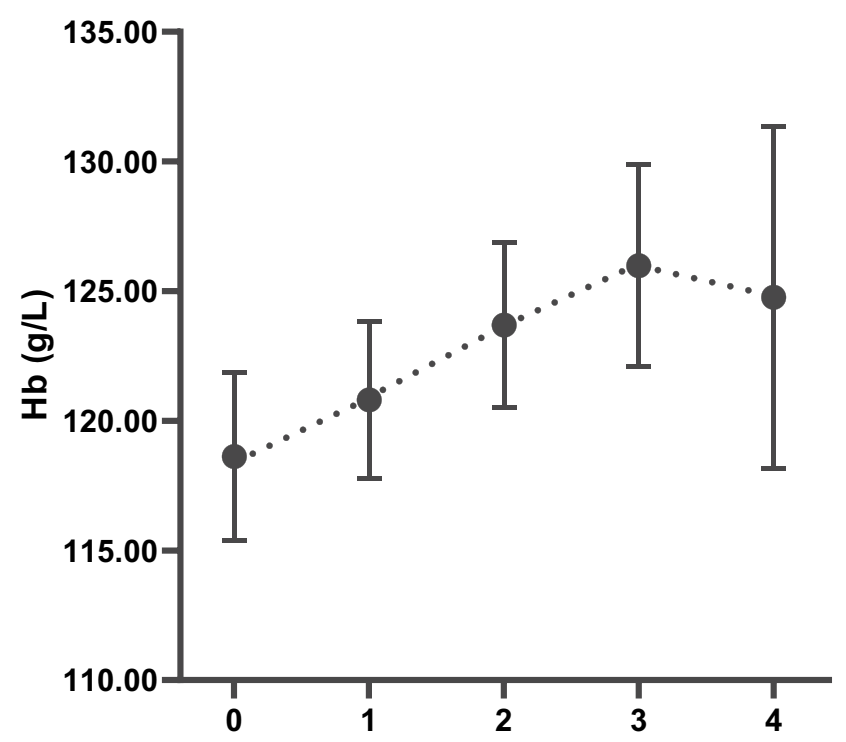

Sum of metabolic syndrome components

Figure 2 The relationship between RBC level, $\mathrm{Hb}$ level and the sum of MetS components. Circles denote the mean. Lower and upper bars indicate $95 \%$ confidence interval (RBC: $P=0.002 ; \mathrm{Hb}: \mathrm{P}=0.042$ )

Abbreviations: $\mathrm{RBC}$, red blood cell count; $\mathrm{Hb}$, hemoglobin.

\section{Effect of RBC and MetS Components on Deep Myometrial Invasion of EEC}

We also analyzed the influence of: (a) the MetS status, (b) the number of MetS criteria met, (c) each individual criterion of MetS, and (d) circulating RBC and $\mathrm{Hb}$ levels on deep myometrial invasion of EEC (Table 4). A significant association was observed between the risk of deep myometrial invasion in our cohort of patients and menopause. Remarkably, after adjusting for age, menopausal status, each individual criterion of MetS and tumor markers, obesity was significantly associated with a higher risk of deep myometrial invasion $(\mathrm{OR}=2.101,95 \% \mathrm{Cl}=$ $1.128-3.916, \mathrm{P}=0.019)$. Furthermore, our results showed that the risk of deep myometrial invasion increased with a decrease in the RBC quartiles ( $\mathrm{P}=0.037)$, and the risk of deep muscle infiltration increased by 2.806 -fold $(95 \% \mathrm{Cl}=1.311-6.005, \mathrm{P}=$ 0.008 ) in patients with the lowest RBC quartile (Q1) compared with those in the reference group (Q4). However, we did not find any association between $\mathrm{Hb}$ and the risk of deep myometrial invasion. Multivariate logistic regression analysis indicated that menopausal status, obesity, RBC, and CA125 were the independent risk factors correlated with deep myometrial invasion.

Further exploratory analyses were carried out to evaluate the association of RBC with deep myometrial invasion in different MetS states. After adjusting for age, the lowest RBC quartile (Q1) had a 3.842-fold increased risk of deep myometrial invasion in EEC patients with MetS compared with those in the reference group (Q4). Similarly, in patients with two or more MetS criteria or with obesity and hyperglycemia, the lowest RBC quartile (Q1) was a risk factor for deep myometrial invasion compared with the reference group $(\mathrm{Q} 4)(\mathrm{OR}=3.836, \mathrm{P}=0.004,95 \% \mathrm{CI}=$ 1.533-9.596; OR $=2.961, \mathrm{P}=0.022,95 \% \mathrm{CI}=1.170-7.497$; $\mathrm{OR}=4.109, \mathrm{P}=0.015,95 \% \mathrm{CI}=1.323-11.759)$. However, no association was observed between low RBC levels and deep myometrial invasion in patients without MetS or $\leq$ two MetS criteria or with obesity and hyperglycemia $(\mathrm{P}>0.05$, Figure 3$)$. Risk of deep myometrial invasion in EEC patients with MetS, low RBC to others are shown in Supplementary Figure 2.

\section{Discussion}

In this cross-sectional study, we found higher $\mathrm{RBC}$ and $\mathrm{Hb}$ levels in EEC patients with MetS. Preoperative MetS especially obesity or hyperglycemia are risk factors for deep myometrial invasion of EEC. Low RBC levels increased the risk of deep myometrial invasion in EEC patients with MetS and its components.

Over the past decades, the prevalence of MetS has increased dramatically worldwide. ${ }^{10}$ According to the criteria set forth by the Chinese Diabetes Society in 2004 in the China Health and Nutrition Survey in 2009, the prevalence of MetS among female participants aged 18 years and above was $8.7 \%$, and the prevalence of MetS correlated positively with age. ${ }^{10}$ The prevalence of MetS was $16.2-17.0 \%$ according to the data assessed by the CDS criteria for other cancer patients in Fujian Province, 


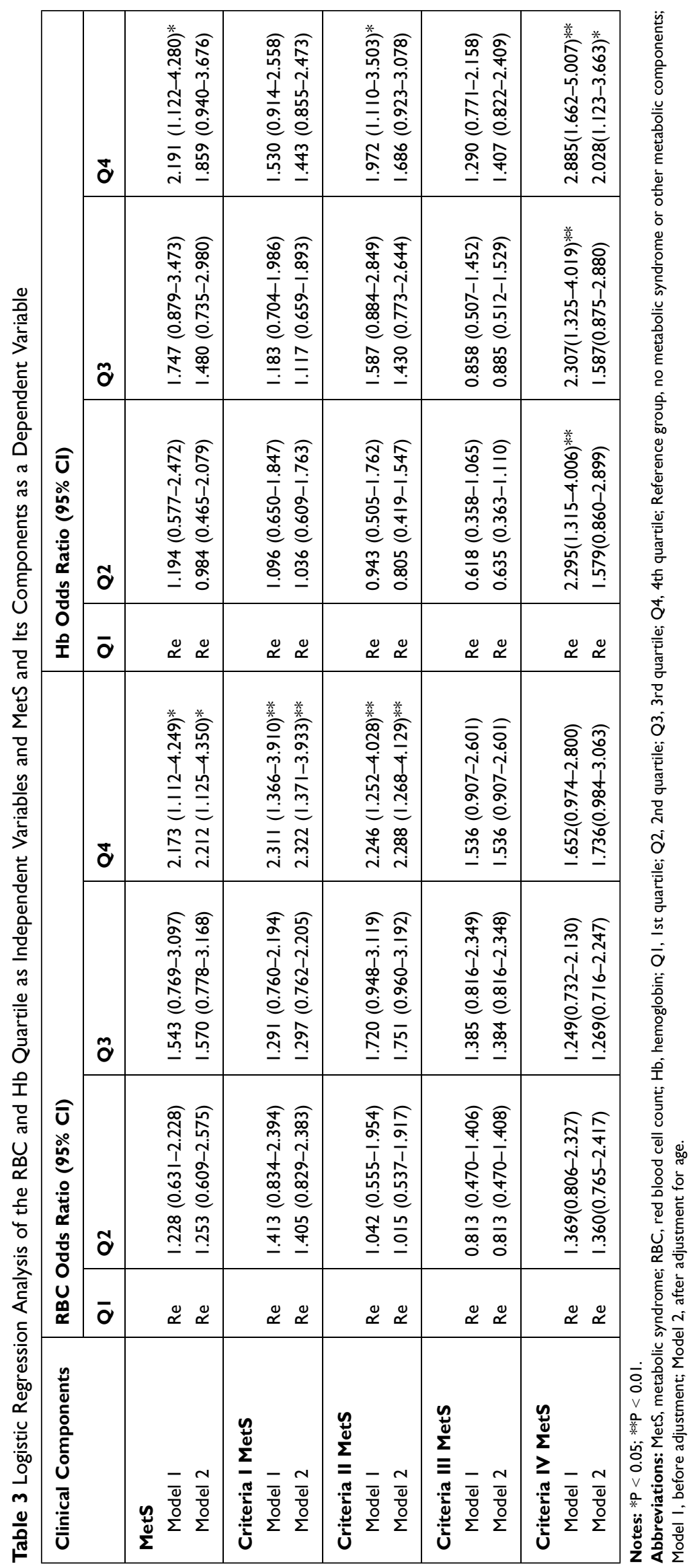


Table 4 Univariate Analysis Showing the Influence of RBC, Hb, and MetS on Deep Myometrial Invasion of EEC

\begin{tabular}{|c|c|c|c|c|c|c|}
\hline Variables & OR & 95\% Cl (OR) & $\mathbf{P}$ & OR' & 95\% Cl' (OR) & P' \\
\hline Age $\geq 50$ vs $<50$ (years) & 2.870 & $1.617-5.096$ & $<0.001 * *$ & 1.070 & $0.425-2.696$ & 0.886 \\
\hline Menopause Yes vs No & 3.752 & $2.213-6.361$ & $<0.00 I^{* *}$ & 3.930 & $1.672-9.235$ & $0.002 * *$ \\
\hline The quartiles of RBC & 1.284 & $1.054-1.563$ & $0.013^{*}$ & - & - & $0.037^{*}$ \\
\hline RBC Q3 vs Q4 & 1.330 & $0.684-2.586$ & 0.400 & 1.363 & $0.637-2.916$ & 0.425 \\
\hline RBC Q2 vs Q4 & 1.679 & $0.88 I-3.200$ & 0.115 & 2.164 & $1.015-4.615$ & $0.046^{*}$ \\
\hline RBC QI vs Q4 & 2.109 & $1.121-3.969$ & $0.021 *$ & 2.806 & $1.311-6.005$ & $0.008 * *$ \\
\hline The quartiles of $\mathrm{Hb}$ & 1.028 & $0.848-1.247$ & 0.777 & - & - & - \\
\hline $\mathrm{Hb}$ Q3 vs Q4 & 0.870 & $0.468-1.618$ & 0.660 & - & - & - \\
\hline Hb Q2 vs Q4 & 1.034 & $0.536-1.898$ & 0.915 & - & - & - \\
\hline Hb QI vs Q4 & 1.037 & $0.568-1.894$ & 0.906 & - & - & - \\
\hline MetS & 2.857 & $1.738-4.698$ & $<0.00 I^{* *}$ & 1.327 & $0.534-3.301$ & 0.543 \\
\hline Criteria I MetS & 1.989 & $1.285-3.079$ & $0.002^{* *}$ & 2.101 & $1.128-3.916$ & $0.019 *$ \\
\hline Criteria II MetS & 2.030 & $1.283-3.213$ & $0.002 * *$ & 1.385 & $0.703-2.725$ & 0.346 \\
\hline Criteria III MetS & 0.920 & $0.624-1.529$ & 0.977 & - & - & - \\
\hline Criteria IV MetS & 1.780 & $1.151-2.754$ & $0.010 *$ & 1.248 & $0.695-2.241$ & 0.458 \\
\hline \multicolumn{7}{|l|}{ CAI25 (U/mL) } \\
\hline$\geq 35$ vs $<35$ & 3.244 & $2.009-5.239$ & $<0.001 * *$ & 2.753 & $1.452-5.222$ & $0.002 * *$ \\
\hline \multicolumn{7}{|l|}{ CAI5-3 (U/mL) } \\
\hline$\geq 28$ vs $<28$ & 2.132 & $0.755-6.018$ & 0.153 & - & - & - \\
\hline \multicolumn{7}{|l|}{ CAI9-9 (U/mL) } \\
\hline$\geq 27$ vs $<27$ & 3.412 & $2.053-5.67 \mid$ & $<0.00 I^{* *}$ & 1.705 & $0.909-3.200$ & 0.096 \\
\hline
\end{tabular}

Notes: $* \mathrm{P}<0.05 ; * * \mathrm{P}<0.01$.

Abbreviations: MetS, metabolic syndrome; RBC, red blood cell count; Hb, hemoglobin; QI, Ist quartile; Q2, 2nd quartile; Q3, 3rd quartile; Q4, 4th quartile; CAI25, cancer antigen 125; CAI5-3, cancer antigen 15-3; CA19-9, cancer antigen 19-9; ', multivariate logistic analysis.

China. ${ }^{11,12}$ The prevalence of MetS among the older patients in our study was relatively high, at $18.8 \%$.

Increased erythropoiesis in EEC patients with MetS has been found in a number of previous studies in different populations. ${ }^{13,14}$ Increased erythrocyte parameters may be a new aspect of the insulin resistance syndrome. In this EEC population, we also found that $\mathrm{RBC}$ and $\mathrm{Hb}$, especially $\mathrm{RBC}$, were positively correlated with the presence of MetS components and the number of MetS components. The association of erythrocytes with MetS and its components can be explained by the fact that EEC patients often present with complications such as hyperinsulinemia and insulin resistance. Studies have shown that human insulin can directly act on erythrocyte progenitor cells and promote erythropoiesis. ${ }^{15}$ In vitro studies have also shown that insulin and insulin-like growth factor I can promote the proliferation and differentiation of human bone marrow and circulating erythroid progenitors into erythrocytes. ${ }^{16}$ The increase of erythropoiesis may be a new MetS parameter for EEC patients.
Myometrial invasion is a well-known predictor of recurrence of endometrial cancer and is important in the decision-making of adjuvant therapy. ${ }^{1,17}$ Previous studies have found that MetS is closely related to the stage, grade, vascular invasion, and lymph node metastasis of endometrial carcinoma, and is an independent prognostic factor of EEC. ${ }^{3}$ However, the correlation between metabolic abnormalities and myometrial infiltration is not clear. Diabetes mellitus is associated with poor recurrence-free survival (RFS) and overall survival in type I endometrial cancer. ${ }^{18}$ Obesity is associated with high morbidity and mortality of endometrial cancer. ${ }^{19}$ Obesity can affect the RFS of women with a high risk of endometrial cancer. ${ }^{20,21}$ After adjusting for BMI, the association between various lipid levels and the tumor risk was generally reduced, suggesting that a large part of the association between abnormal lipid metabolism and tumors is mediated by obesity. Our findings also showed a positive correlation between obesity, abnormal blood glucose, and myometrial invasion, which means that MetS is associated with features of an aggressive tumor biology. 


RBC
Q1 v1 vs Q4
Q2 v4
Qets - Q3 vs Q4
Q2 vs Q4

Figure 3 The quartile of RBC associated with the risk of deep myometrial invasion according to different MetS states.

Notes: $* \mathrm{P}<0.05 ; * * \mathrm{P}<0.01$.

Abbreviations: MetS, metabolic syndrome; RBC, red blood cell count; Hb, hemoglobin; HR, hazard ratio; QI, Ist quartile; Q2, 2nd quartile; Q3, 3rd quartile; Q4, 4th quartile.

An interesting aspect of this study is the relationship between anemia-related erythrocyte parameters and myometrial invasion of EEC in patients with MetS. Anemia and several types of cancer originating in different organs are associated with advanced disease and poor prognosis, including the breast and ovaries. ${ }^{22,23}$ For endometrial cancer, previous studies have shown that low $\mathrm{Hb}$ is associated with advanced EEC and low survival rates. ${ }^{24,25}$ Other studies have shown the association between decreased $\mathrm{Hb}$ before treatment and poor histopathological features, but it is not regarded as an independent factor for poor survival in multivariate analysis. ${ }^{26}$ However, there are few studies on RBC levels and the prognosis of EEC. Our study showed that the anemia-related erythrocyte parameter $\mathrm{RBC}$ rather than $\mathrm{Hb}$ was associated with myometrial invasion of EEC. In EEC patients with MetS, the decrease in $\mathrm{RBC}$ is associated with deep myometrial invasion especially in those with obesity and hyperglycemia.

The reason for this pattern is not obvious. Cancerrelated anemia leads to a decrease in $\mathrm{RBC}$ and $\mathrm{Hb}$ and is caused by multiple factors. These could be nutritional deficiency, iron metabolism disorder, chronic systemic inflammation, and tumor bone marrow infiltration. ${ }^{27}$ Since EEC is most often diagnosed without distant metastases, the observed reduction of $\mathrm{RBC}$ and $\mathrm{Hb}$ may be caused by something other than direct bone marrow infiltration. It is convincing to attribute anemia to concurrent uterine bleeding, which is a potential confounding factor. Anemia is also considered to be a paraneoplastic syndrome, a phenomenon of cancer biological invasion. 
Tumor cells produce and secrete several soluble cytokines (such as interleukin-1, interferon- $\gamma$, and tumor necrosis factor) that may reduce the levels of $\mathrm{RBC}$ and $\mathrm{Hb}$ by hemolysis, inhibition of erythropoietin production, and damage of the erythropoietin response of erythroid bone marrow precursors. ${ }^{28}$ In addition, cancer produces cytokines that cause systemic inflammation, thereby reducing the production of red blood cells and shortening their survival time. MetS is also associated with chronic subclinical inflammation caused by high levels of pro-inflammatory mediators, and secondary inflammation may coordinate the occurrence and development of cancer through local and systemic processes. ${ }^{5}$ Therefore, we propose that in EEC patients with dysregulation of glycolipid metabolism, the remodeling of the tumor immune microenvironment may make the decreased RBC more closely related to tumorigenesis and development.

This study had some limitations. Without access to data on the drug treatment of MetS, it was impossible to adjust the effect of MetS treatment in the patients with EEC. This may have led to systematic bias, confounding of the association of MetS and its components with erythrocyte parameters and its possible causal relationship with poor prognosis. In addition, there were no other basic hematological parameters in our population-based study design to characterize the type of anemia, nor did it take into account the control of inflammatory conditions that may have a potential impact on hematopoietic organs to minimize potential bias.

\section{Conclusion}

In conclusion, our results show that the prevalence of MetS in patients with EEC is high, and MetS is often accompanied by increased $\mathrm{RBC}$ and $\mathrm{Hb}$, while decreased $\mathrm{RBC}$ rather than $\mathrm{Hb}$ is a risk factor for deep myometrial invasion in EEC patients, especially those with MetS. Given the high prevalence of MetS in EEC, clinicians may be able to identify individuals at high risk for prognosis early on by closely monitoring metabolic abnormalities and giving guidance for a healthy lifestyle. In addition, it is recommended that $\mathrm{RBC}$ be included in the prognostic assessment of EEC patients, especially those with metabolic abnormalities since RBC may be a new marker of poor prognosis in EEC patients with metabolic disorders.

\section{Acknowledgments}

This research did not receive any specific grant from funding agencies in the public, commercial, or not-forprofit sectors.

\section{Disclosure}

The authors report no conflicts of interest in this work.

\section{References}

1. Morice P, Leary A, Creutzberg C, Abu-Rustum N, Darai E. Endometrial cancer. Lancet. 2016;387(10023):1094-1108. doi:10.10 16/S0140-6736(15)00130-0

2. Samson SL, Garber AJ. Metabolic syndrome. Endocrinol Metab Clin North Am. 2014;43(1):1-23. doi:10.1016/j.ecl.2013.09.009

3. Ni J, Zhu T, Zhao L, et al. Metabolic syndrome is an independent prognostic factor for endometrial adenocarcinoma. Clin Transl Oncol. 2015;17(10):835-839. doi:10.1007/s12094-015-1309-8

4. Greten FR, Grivennikov SI. Inflammation and cancer: triggers, mechanisms, and consequences. Immunity. 2019;51(1):27-41. doi:10.1016/j.immuni.2019.06.025

5. Yang X, Wang J. The role of metabolic syndrome in endometrial cancer: a review. Front Oncol. 2019;9:744. doi:10.3389/fonc.20 19.00744

6. Weiss G, Ganz T, Goodnough LT. Anemia of inflammation. Blood. 2019;133(1):40-50. doi:10.1182/blood-2018-06-856500

7. Nagle CM, Crosbie EJ, Brand A, et al. The association between diabetes, comorbidities, body mass index and all-cause and causespecific mortality among women with endometrial cancer. Gynecol Oncol. 2018;150(1):99-105. doi:10.1016/j.ygyno.2018.04.006

8. Mardi T, Toker S, Melamed S, et al. Increased erythropoiesis and subclinical inflammation as part of the metabolic syndrome. Diabetes Res Clin Pract. 2005;69(3):249-255. doi:10.1016/j.diabres.2005. 01.005

9. Chinese Medical Association. The Suggestion on Chinese Metabolic Syndrome. Shanghai, China: Chinese Medical Association, 2004.

10. Xi B, He D, Hu Y, Zhou D. Prevalence of metabolic syndrome and its influencing factors among the Chinese adults: the China health and nutrition survey in 2009. Prev Med. 2013;57(6):867-871. doi:10.1016/j.ypmed.2013.09.023

11. Peng F, Hu D, Lin X, et al. Preoperative metabolic syndrome and prognosis after radical resection for colorectal cancer: the Fujian prospective investigation of cancer (FIESTA) study. Int $J$ Cancer. 2016;139(12):2705-2713. doi:10.1002/ijc.30404

12. Hu D, Peng F, Lin X, et al. Preoperative metabolic syndrome is predictive of significant gastric cancer mortality after gastrectomy: the Fujian Prospective Investigation of Cancer (FIESTA) Study. EBioMedicine. 2017;15:73-80. doi:10.1016/j.ebiom.2016.12.004

13. Huang LL, Dou DM, Liu N, et al. Association of erythrocyte parameters with metabolic syndrome in the Pearl River Delta region of China: a cross sectional study. BMJ Open. 2018;8(1):e19792. doi:10.1136/bmjopen-2017-019792

14. Wu S, Lin H, Zhang C, et al. Association between erythrocyte parameters and metabolic syndrome in urban Han Chinese: a longitudinal cohort study. BMC Public Health. 2013;13:989. doi:10.1186/ 1471-2458-13-989

15. Aoki I, Taniyama M, Toyama K, Homori M, Ishikawa K. Stimulatory effect of human insulin on erythroid progenitors (CFU-E and BFU-E) in human $\mathrm{CD} 34+$ separated bone marrow cells and the relationship between insulin and erythropoietin. Stem Cells. 2010;12(3):329-338. doi:10.1002/stem.5530120309

16. Miyagawa S, Kobayashi M, Konishi N, Sato T, Ueda K. Insulin and insulin-like growth factor I support the proliferation of erythroid progenitor cells in bone marrow through the sharing of receptors. Br J Haematol. 2000;109(3):555-562. doi:10.1046/j.1365-2141.2000.02047.x

17. Ruz-Caracuel I, Ramón-Patino JL, López-Janeiro Á, et al. Myoinvasive pattern as a prognostic marker in low-grade, earlystage endometrioid endometrial carcinoma. Cancers. 2019;11 (12):1845. doi:10.3390/cancers 11121845 
18. Ko EM, Walter P, Clark L, et al. The complex triad of obesity, diabetes and race in type I and II endometrial cancers: prevalence and prognostic significance. Gynecol Oncol. 2014;133(1):28-32. doi:10.1016/j.ygyno.2014.01.032

19. Onstad MA, Schmandt RE, Lu KH. Addressing the role of obesity in endometrial cancer risk, prevention, and treatment. J Clin Oncol. 2016;34(35):4225-4230. doi:10.1200/JCO.2016.69.4638

20. Shaw E, Farris M, McNeil J, Friedenreich C. Obesity and endometrial cancer. Recent Results Cancer Res. 2016;208:107-136.

21. Canlorbe G, Bendifallah S, Raimond E, et al. Severe obesity impacts recurrence-free survival of women with high-risk endometrial cancer: results of a French Multicenter Study. Ann Surg Oncol. 2015;22 (8):2714-2721. doi:10.1245/s10434-014-4295-0

22. Qiu MZ, Xu RH, Ruan DY, et al. Incidence of anemia, leukocytosis, and thrombocytosis in patients with solid tumors in China. Tumour Biol. 2010;31(6):633-641. doi:10.1007/s13277-010-0079-8

23. Gerestein CG, Eijkemans MJ, de Jong D, et al. The prediction of progression-free and overall survival in women with an advanced stage of epithelial ovarian carcinoma. BJOG. 2009;116(3):372-380. doi:10.1111/j.1471-0528.2008.02033.x
24. Metindir J, Bilir Dilek G. Preoperative hemoglobin and platelet count and poor prognostic factors in patients with endometrial carcinoma. $J$ Cancer Res Clin Oncol. 2009;135(1):125-129. doi:10.1007/s00432008-0430-2

25. Njølstad TS, Engerud H, Werner HM, Salvesen HB, Trovik J. Preoperative anemia, leukocytosis and thrombocytosis identify aggressive endometrial carcinomas. Gynecol Oncol. 2013;131 (2):410-415. doi:10.1016/j.ygyno.2013.08.032

26. Tamussino KF, Gücer F, Reich O, Moser F, Petru E, Scholz HS. Pretreatment hemoglobin, platelet count, and prognosis in endometrial carcinoma. Int $J$ Gynecol Cancer. 2001;11(3):236-240. doi:10.1046/j.1525-1438.2001.01024.x

27. Gilreath JA, Stenehjem DD, Rodgers GM. Diagnosis and treatment of cancer-related anemia. Am J Hematol. 2014;89(2):203-212. doi:10.1002/ajh.23628

28. Maccio A, Madeddu C, Gramignano G, et al. The role of inflammation, iron, and nutritional status in cancer-related anemia: results of a large, prospective, observational study. Haematologica. 2015;100475 (1):124-132. doi:10.3324/haematol.2014.112813

\section{Publish your work in this journal}

Cancer Management and Research is an international, peer-reviewed open access journal focusing on cancer research and the optimal use of preventative and integrated treatment interventions to achieve improved outcomes, enhanced survival and quality of life for the cancer patient.
The manuscript management system is completely online and includes a very quick and fair peer-review system, which is all easy to use. Visit http://www.dovepress.com/testimonials.php to read real quotes from published authors. 